\title{
Acid-base treated vermiculite as high performance adsorbent: Insights into the mechanism of cationic dyes adsorption, regeneration, recyclability and stability studies
}

\author{
Wojciech Stawiński ${ }^{\text {a }}$, Agnieszka Wgrzyn ${ }^{\text {b, }}{ }^{*}$, Tomasz Dańko b , Olga Freitas a , \\ Sónia Figueiredo ${ }^{\mathrm{a}}$, Lucjan Chmielarz ${ }^{\mathrm{b}}$
}

\author{
a REQUIMTE, LAQV, Instituto Superior de Engenharia do Porto, Instituto Politécnico do Porto, Rua Dr. António Bernardino de Almeida 431, 4200-072, Porto, \\ Portugal \\ ${ }^{\mathrm{b}}$ Faculty of Chemistry, Jagiellonian University, ul. Ingardena 3, 30-060, Kraków, Poland
}

H I G H L I G H T S

- Combined $\mathrm{NaOH} /$ acid treatment of vermiculite increased its adsorption capacity.

- Mixture of $\mathrm{EtOH}$ and $\mathrm{NaCl}$ solution was used for eficient adsorbent regeneration.

- Different behavior of dyes was observed in binary mixtures.

- Recyclable use of adsorbent for cationic textile dyestuffs removal was achieved.

- High adsorption level was maintained in a constant flow column system in 7 cycles.
G R A PH I C A L A B S T R A C T

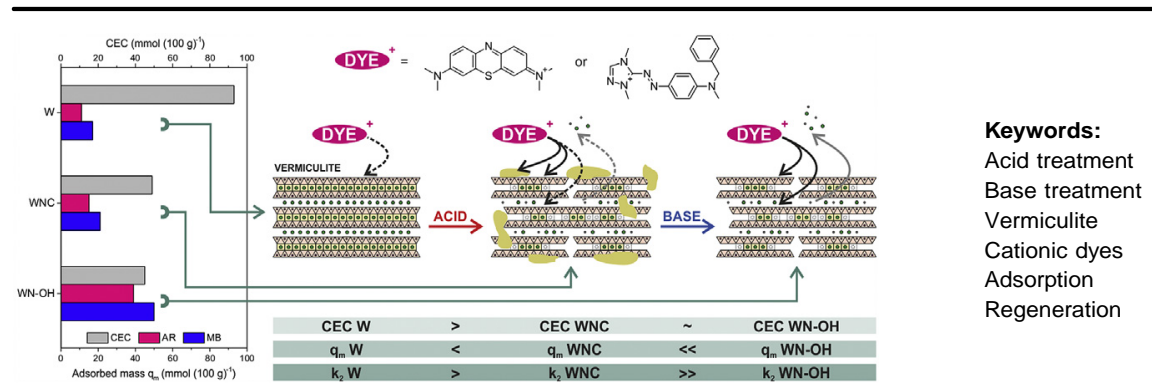




\section{Introduction}

Developing industry and increasing human population contribute greatly to deterioration of water quality. The European Union took step in keeping water in good condition by adopting Water Framework Directive 2000/60/CE (with subsequent changes by $2455 / 2001 / C E, 2006 / 11 / C E, 2008 / 32 / C E, 2008 / 105 / C E, 2009 / 31 /$ CE, 2013/39/UE and 2014/101/UE), and Industrial Emissions Directive (2010/75/EU). Those documents determined priority substances to be eliminated from wastewaters and foned the obligations to be met by industrial activities, to avoid pollution, take preventive measures against it, and reduce, recycle and dispose of waste in the manner that generates less pollution. Chemical methods need the use of excess chemicals. In chemical methods, some toxic byproducts may occur[(uman et al., 2015a).

Dyes are common in efluents discharged by various industries such as paper, plastics, food, cosmetics, and textileA(ngin et al., 2013; Rozada et al., 2003. They usually have complex molecular structure, some of them may have toxic or carcinogenic effects on animals, they are hard to degrade biologically and change the light penetration in receiving waters disturbing natural biological processes. Moreover, they are one of the most problematic and fifult types of pollutant to be treated by conventional methods (Bhatnagar and Jain, 2005; Forgacs et al., 2004; Reife and Freeman, 1996).

Coagulationflocculation methods are often applied to treat colored waters but their operation cost is high due to chemicals addition and sludge management!(Iall et al., 2005). In the need of efficient and sustainable methods adsorption has been getting more interest in the application to wastewaters treatmentẹit ão and Serrão, 2005). It is considered as one of the best wastewater treatment methods due to its universal nature, ease of operation, ability to remove soluble and insoluble organic pollutants, high removal capacity and possibility to recycle and reuse many of adsorbents (Ali et al., 2012; Pan et al., 2009. One of the most commonly used adsorbents is activated carbon, having granular, powder, fiber and cloth form, due to its high spefic surface area and high adsorption capacity for pollutants/(yranci and Duman, 2009; Duman and Ayranci, 2006, 2010 However it is relatively expensive what makes it unattractive for discoloration purposes (Rozada et al., 2003). It is necessary to use an adsorbent that is freely available, inexpensive and non-hazardous in nature (i et al., 2012). Clays show good perspectives in thifield.

Clays are minerals that have layer structure based on a tetrahedral $(\mathrm{T})$ and an octahedral $(\mathrm{O})$ phyllosilicate sheets, that may condense in either a $1: 1$ or $2: 1$ proportion to form $\mathrm{T}-\mathrm{O}$ or $\mathrm{T}-\mathrm{O}-\mathrm{T}$ layer (Bergaya and Lagaly, 200\%. If a charge is present on the sheets it is balanced by an ion located in between the sheets. These charge-balancing ions can be exchanged resulting in very good ionexchange properties of the material (chmielarz et al., 2003). Vermiculite is a clay mineral clasfied as 2:1 phyllosilicate Bailey and Chairman, 1980; Rieder et al., 1998 Vermiculite is very abundant and much cheaper compared with other clays. Owing to its remarkable features, vermiculite is commonly used in agricultural, industrial and environmental applications (Duman and Tunç, 2008; Duman et al., 2015b). It can be a subject to modfications in order $_{108}$ enhance its eficiency for the removal of pollutants from wastewaters (Ali et al., 2012).

Mechanism of adsorption on a clay particle surface can take place via three mechanisms involving formation of complexes with charged surface functional groups: inner-sphere surface complexes (mostly ionic and covalent bonding), outer-sphere surface complexes and formation of diffuse-ion swarm, when the cation screens a delocalized surface charge. The last two mechanisms involve mostly electrostatic bonding. Ions adsorbed by outersphere complexes and diffuse-ion swarm are readily exchangeable and can be easily leached from the clays(posito, 2008). Hence, the mechanism of adsorption determinates also possibility for regeneration and recycling of an adsorbent.

Acid activation of vermiculite is a common method of treatment of this clay however, to the best of authors' knowledge, little is known about complex modfications of already treated materials. The aim of this research was to investigate if any additional step to acid activation of vermiculite might result in further increase in the maximum adsorption capacity of the material. As shown in this work, when that modfication is followed by treatment with a base it results in even more signficant increase in the adsorption capacity compared to only acid treatment. The base treatment enhances the physicochemical characteristics of the material. The extensive adsorption experiments in batch and continuoufow (fixed bed column), as well as regeneration studies demonstrate the high performance of these materials, which offer interesting possibilities for industrial application as economical and sustainable adsorbent.

\section{Experimental section}

\subsection{Materials}

Vermiculite from South Africa (raw vermiculite, W) and its expanded derivative (Ve, obtained by rapid heating up to $1000^{\circ} \mathrm{C}$ ) were kindly supplied by ROMINCO POLSKA Sp. z o.o. Samples of acid activated vermiculite (WNC) were prepared by treating the raw material (W) for $2 \mathrm{~h}$ in $1.8 \mathrm{M}$ nitric acid at $98^{\circ} \mathrm{C}$ and then during $1 \mathrm{~h}$ in $10 \%$ citric acid solution at room temperature $\left(24^{\circ} \mathrm{C}\right)$ following the procedure described in previous studys(tawi ński et al., 2016). Experiments were conducted in Erlenmeyeflasks with caps or a reflux condenser in case where elevated temperature was used.

The basic dyestuffs methylene blue (MB), CI 52015, supplied by Riedel de Haen and astrazon red FBL 200\% (AR), CI 85496-37-3, supplied by Dystar, were used for adsorption experiment $\$$ ig. A.1 in the Supplementary Material).

In the first step $1 \mathrm{~g}$ of WNC and W were mixed with $10 \mathrm{~mL}$ of $1 \mathrm{M}$ $\mathrm{NaOH}$ and stirred for $2 \mathrm{~h}$ and $24 \mathrm{~h}$, after that, samples were washed, centrifuged ( 5 cycles of $10 \mathrm{~min}$ at $4000 \mathrm{rpm}$, Sartorius, Sigma 2-16) and left to dry. In the next step, in order to obtain base treated samples (WN-OH), weighted portions of $1 \mathrm{~g}$ of WNC were mixed with $10 \mathrm{~mL}$ of $\mathrm{NaOH}$ solutions of different concentrations $(0.5 \mathrm{M}$, $1 \mathrm{M}, 1.5 \mathrm{M}$ and $2 \mathrm{M}$, respectively), stirred during $2 \mathrm{~h}$ at room temperature, washed and left to dry. In the last step, four samples of $1 \mathrm{~g}$ of WNC were placed inflasks with $10 \mathrm{~mL}$ of $0.5 \mathrm{M} \mathrm{NaOH}$ and stirred during $2 \mathrm{~h}$ and $4 \mathrm{~h}$ at different temperatures (room temperature $\left(24^{\circ} \mathrm{C}\right.$ ) and $\left.98^{\circ} \mathrm{C}\right)$, a reflux condenser was used where elevated temperature was applied.5 


\subsection{Methods}

The structure of the materials was studied with X-ray powder diffractometer (Bruker, D2 PHASER) equipped with $\mathrm{CuK} \alpha$ radiation source (measurement range: $z 70 \circ 2 \theta$, step size: $0.02^{\circ} 2 \theta$, counting time: $1 \mathrm{~s}$ per step, slit width: $0.6 \mathrm{~mm}$ ). Infrared spectra of the samples diluted with $\mathrm{KBr}$ (4 mg of sample ground with $96 \mathrm{mg}$ of $\mathrm{KBr}$ ) were recorded in the range of $6504000 \mathrm{~cm}^{-1}$ with resolution of $2 \mathrm{~cm}^{-1}$ (200 scans), using diffused relectance technique (Nicolet 6700 FT-IR, Thermo Scientfic, MCT/A detector). The textural parameters of the samples were determined by adsorption of $\mathrm{N}_{2}$ at $-196{ }^{\circ} \mathrm{C}$ using a Quantachrome surface area and pore size analyzer, model $2200 \mathrm{E}$, on outgassed samples $\left(25^{\circ} \mathrm{C}, 2 \mathrm{~h}\right.$, pressure 0.001 bar). MB area was calculated based on adsorption studies of methylene blue taking $130 \AA^{2}$ as the surface occupied by one molecule of the dye. Cation exchange capacity was determined using the ammonium acetate method Steudel, 2008). Chemical composition of samples was determined using atomic absorption spectroscopy (AAS) (Analytic Jena High-Resolution Continuum Source Atomic Absorption Spectrometer, ContrAA 700) method. The results are presented only for the most abundant elements (>0.25 wt\%). Point of zero charge was determined using two different methods: according to procedures described by Mular (Mular and Roberts, 1966 and Riviera (Rivera-Utrilla et al., 2001) and given as an average of four $\mathrm{pH}$ values obtained in the experiment. The SEM/EDS analysis was performed using a High resolution (Schottky) Environmental Scanning Electron Microscope with XRay Microanalysis and Electron Backscattered Diffraction analysis: Quanta 400 FEG ESEM/EDAX Genesis X4M. Samples were coated with an $\mathrm{Au} / \mathrm{Pd}$ thinfilm by sputtering, using the SPI Module Sputter Coater equipment.

Adsorbate concentration in batch adsorption experiments was measured using UV-VIS spectrophotometer (Thermo Scieiftud, Evolution 300) at the maximum absorbance wavelength (665 nm for $\mathrm{MB}$ and $531 \mathrm{~nm}$ for $\mathrm{AR}$ ).

Models were fitted to the experimental data gathered in the kinetics, equilibrium and column experiments using non-linear regression analysis. Variances and correlation coffients were determined and compared using Fisher's, and Akaike's Information Criterion (AIC) tests.

The pseudo 1st order Lagergren's modelL(agergren, 1898) and the pseudo 2nd order Ho's model Iflo and McKay, 1999 werefitted for the kinetic data, the Langmuir's I(angmuir, 1918) and the Freundlich's (Freundlich, 1906) models were fitted to the adsorption isotherm data. In the column experiments Yan's modelán et al., 2001) was fitted to the experimental data in order to determine the maximum adsorption capacity of the materials and YoonNelson's model (Yoon and Nelson, 1984 to obtain breakthrough times. Models equations and description are given in section 2 . in the Supplementary Material.

Batch adsorption experiments were performed in Erlenmeyer flasks with caps and a magnetic stirrer (Velp, Multistirrer 15) at room temperature $\left(24{ }^{\circ} \mathrm{C}\right)$, without $\mathrm{pH}$ adjustment. Portions of $20 \mathrm{mg}$ of each sample was placed in flask and mixed with $50 \mathrm{~mL}$ of a $50 \mathrm{mg} \mathrm{L}^{-1}$ solution of AR or MB, stirred for $2 \mathrm{~h}$, centrifuged ( $5 \mathrm{~min}$ in $4500 \mathrm{rpm}$, Sartorius, Sigma 2-16) and concentration of adsorbate in the supernatant determined.

Kinetic experiments were carried out at room temperature $\left(24{ }^{\circ} \mathrm{C}\right.$ ) using a magnetic stirrer (Velp, Multistirrer 15), without $\mathrm{pH}$ adjustment. A mass of $250 \mathrm{mg}$ of the material was placed infask with $500 \mathrm{~mL}$ of dyestuff solution with an initial concentration of $100 \mathrm{mg} \mathrm{L}^{-1}$. Samples were collected in selected time intervals using a micropipette and immediately centrifuged (1 min in $4500 \mathrm{rpm}$, Sartorius, Sigma 2-16) and concentration of the supernatant was determined.
Equilibrium studies were performed in $100 \mathrm{~mL}$ Erlenmeyer flasks with caps and $50 \mathrm{~mL}$ of dyes solutions of two concentrations (50 $\mathrm{mg} \mathrm{L}^{-1}$ and $100 \mathrm{mg} \mathrm{L}^{-1}$ ) and varying amount of material (from $10 \mathrm{mg}$ to $250 \mathrm{mg}$ ). Suspensions were agitated on a stirrer (Velp, Multistirrer 15) for $2 \mathrm{~h}$, samples were collected, centrifuged (Sartorius, Sigma 2-16) and concentration of supernatant was determined.

Colum experiments were performed using a glass column (Omnifit, $2.5 \mathrm{~cm}$ inside diameter, $15 \mathrm{~cm}$ height) and a peristaltic pump (Gilson, Miniplus 3). The studies were carried out with dyes concentration of $50 \mathrm{mg} \mathrm{L}^{-1}$, at room temperature and flow rate of $2.0 \mathrm{~mL} \mathrm{~min}^{-1}$. Weighted portions of $0.5 \mathrm{~g}$ of W and of $0.1 \mathrm{~g}$ of WNC and $\mathrm{NaOH}$ treated material $(\mathrm{WNOH})$, respectively, were mixed with $24 \mathrm{~g}$ of washed sand. In the next step, the column was washed with deionized water for $2 \mathrm{~h}$ and desorption proceeded using a solution of ethanol and sodium chloride, which was considered the best solvent according to the results in section.3, till the effluent showed no color. When the desorption process wafinished, the column was washed with deionized water again and another cycle of adsorption performed ( 7 cycles on the raw material and 5 cycles on the modified materials). Three independent cycles of adsorption and desorption of $\mathrm{MB}$ and $\mathrm{AR}$ onto $\mathrm{WN}-\mathrm{OH}$ were performed, during which changes of $\mathrm{pH}$ were monitored. In the last part of the studies co-adsorption of both dyestuffs was investigated on W, WNC and $\mathrm{WN}-\mathrm{OH}$. In each case the ifluent consisted of a mixture of both dyes in the proportion 50:50 to gefinal concentration of $50 \mathrm{mg}$ of dyes per liter.

Desorption studies were performed by agitating $1 \mathrm{~g}$ of expanded (Ve) and acid activated vermiculite (WNC) in high concentration of AR for $2 \mathrm{~h}$ to prepare saturated material. Samples were washed with distilled water, centrifuged ( 5 cycles, $10 \mathrm{~min}$ at $4000 \mathrm{rpm}$ ) and left to dry. Desorption studies were carried out on saturated samples using different organic and inorganic eluents: cold water $\left(\mathrm{H}_{2} \mathrm{O}\right.$ COLD), hot water $\left(\mathrm{H}_{2} \mathrm{O}\right.$ HOT), hydrogen peroxide (Perox), $0.1 \mathrm{M}$ hydrochloric acid $(\mathrm{HCl})$, sodium chloride solutions $(0.5 \mathrm{M} ; 1 \mathrm{M} ; 5 \mathrm{M}$ respectively) $(\mathrm{NaCl})$; acetone $(\mathrm{Act})$, ethanol $(\mathrm{EtOH})$, chloroform $(\mathrm{Clfm})$, methanol $(\mathrm{MeOH})$, carbon tetrachloride $\left(\mathrm{CCl}_{4}\right)$; mixture (50:50) of ethanol and $1 \mathrm{M}$ aqueous sodium chloride solution $(\mathrm{EtOH}+\mathrm{NaCl})$ and mixture (50:50) of ethanol and $0.5 \mathrm{M}$ nitric acid $\left(\mathrm{EtOH}+\mathrm{HNO}_{3}\right)$. A mass of $100 \mathrm{mg}$ of each saturated sample was put in a flask with a cap and mixed with $50 \mathrm{~mL}$ of eluent and stirred for $2 \mathrm{~h}$ or $24 \mathrm{~h}$. After that time, the regenerated material wassltrated, washed and dried. In the next step, adsorption experiments on the recovered materials were performed by placing $50 \mathrm{mg}$ of each sample in a flask and $100 \mathrm{~mL}$ of dyestuff of concentration of $100 \mathrm{mg} \mathrm{L}^{-1}$ and stirred for $2 \mathrm{~h}$, after which concentrations of solutions were determined.

\section{Results and discussion}

Detailed analysis of the results of spefic surface area measurements and cation exchange capacity are presented in the Supplementary Material in section反.3.1, chemical composition in section S.3.2, point of zero charge determination in section.3.3. $\mathrm{X}$-ray-diffraction analysis in sections.3.4. and diffuse reflectance infrared Fourier transform analysis in section.3.5. Brief overview of obtained results is presented in Supplementary Material (Figures A.2 to A.6).

Particles morphology is visibly changing in each step of treatment. Crystals in starting material are characterized with relatively smooth edges, however between neighboring packets parallel stacking order is not always preserved. Upon acid treatment small clusters of amorphous products were formed and deposited on the surface, moreover numerous fragments of broken platelets may be observed. Leaching in sodium hydroxide solution results in removal 
of irregular and rough particles. X-ray diffraction patterns indicate decrease of particle size as well as basal spacing. As expected, the highest decrease of cation exchange capacity was observed iffrst stage of treatment (acid lixiviation), while it was almost unaltered after contact with solution of base. Results of chemical analysis confirm that components of octahedral layer were dissolved in acid in large extent. Similarly silica content was sigficantly decreased upon leaching in basic solution. Formation of amorphous silica, also confirmed by infrared spectra analysis, was accompanied with large increase of specfic surface area and consecutive decrease after its dissolution. Point of zero charge on the other hand ftrst decreased to rise again to higher values after the second stage of treatment (SeeFig. 1).

\subsection{NaOH treatment optimization}

The raw material treated only with $\mathrm{NaOH}$ did not show any significant increase in the adsorption capacity, which stayed at an average level of $48 \pm 2 \mathrm{mg} \mathrm{g}^{-1}\left(48 \pm 2,45 \pm 2\right.$ and $\left.49 \pm 5 \mathrm{mg} \mathrm{g}^{-1}\right)$ for the raw (W), the raw treated for $2 \mathrm{~h}$ (W2h) and for $24 \mathrm{~h}$ (W24h), respectively. However, if the vermiculite is activated in acid (WNC) prior to the $\mathrm{NaOH}$ treatment, a big increase in the adsorption capacity, which reached an average level of $140+6 \mathrm{mg} \mathrm{g}^{-1}$, was noticed and additionally a slight decrease in the capacity was observed after longer treatment time of $24 \mathrm{~h}$ compared to $2 \mathrm{~h}$ $\left(86 \pm 2 \mathrm{mg} \mathrm{g}^{-1}\right)$ for the WNC and $144 \pm 1$ and $135 \pm 1 \mathrm{mg} \mathrm{g}^{-1}$ for WNC treated with $\mathrm{NaOH}$ for $2 \mathrm{~h}$ (WNC2h) and for $24 \mathrm{~h}$ (WNC24 h), respectively. Neither different concentrations of $\mathrm{NaOH}$, nor time or temperature of the treatment resulted in statistically sigficant differences in the adsorption capacity of the material that was equal to an average level of $145 \pm 7 \mathrm{mg} \mathrm{g}^{-1}$.

\subsection{Kinetic and equilibrium studies}

Pseudo 2nd order model was the bestit according to AIC for both dyes. However, in the case of Fisher's test pseudo 2nd order model fits better for MB but no statistically sigificant difference between the models exists for AR. Adsorption rate decreases after each treatment step for both dyes. Adsorption of MB occurs faster than adsorption of AR in the case of $\mathrm{W}$ and WNC. That trend changes however for $\mathrm{NaOH}$ treated material on which AR exhibits higher adsorption rate (Table 1). The time needed to reach equilibrium on $\mathrm{NaOH}$ treated material was approximately $110 \mathrm{~min}$ and $50 \mathrm{~min}$ for $\mathrm{MB}$ and $\mathrm{AR}$, respectivelyIfig. A.7Ain the Supplementary Material).

Adsorption of each dye followed different mechanisnF(g. A.7B in the Supplementary Material andTable 1). In the case of MB Langmuir's model fits better for the starting (W) and the acid treated material (WNC) and adsorption of AR on those materiafists better to Freundlich's model according to AIC test. Fisher's test however, showed no difference between the models except for adsorption of MB on WNC, where Freundlich's model was a better fit. For the material after the $\mathrm{NaOH}$ treatment, this situation reverses and Langmuir's modelfits better for adsorption of $\mathrm{MB}$ and Freundlich's for adsorption of AR. The results revealed that $\mathrm{NaOH}$ treatment increased greatly the adsorption capacity of vermiculite in relation to the starting material. Based on Lagmuir's model the adsorption capacity raised from $44 \pm 1$ to $155 \pm 11 \mathrm{mg} \mathrm{g}^{-1}$ in the case of AR and from $53 \pm 10$ to $161 \pm 5 \mathrm{mg} \mathrm{g}^{-1}$ for MB, for raw and $\mathrm{NaOH}$ treated material, respectively (able 1).

\subsection{Pre-selection of eluent for regeneration}

Solutions of inorganic substances fig. 2) did not show good desorbing properties (Ve $\mathrm{HCl}$, Ve Perox, Ve $\mathrm{H}_{2} \mathrm{O}$ COLD, Ve $\mathrm{H}_{2} \mathrm{O}$ HOT,
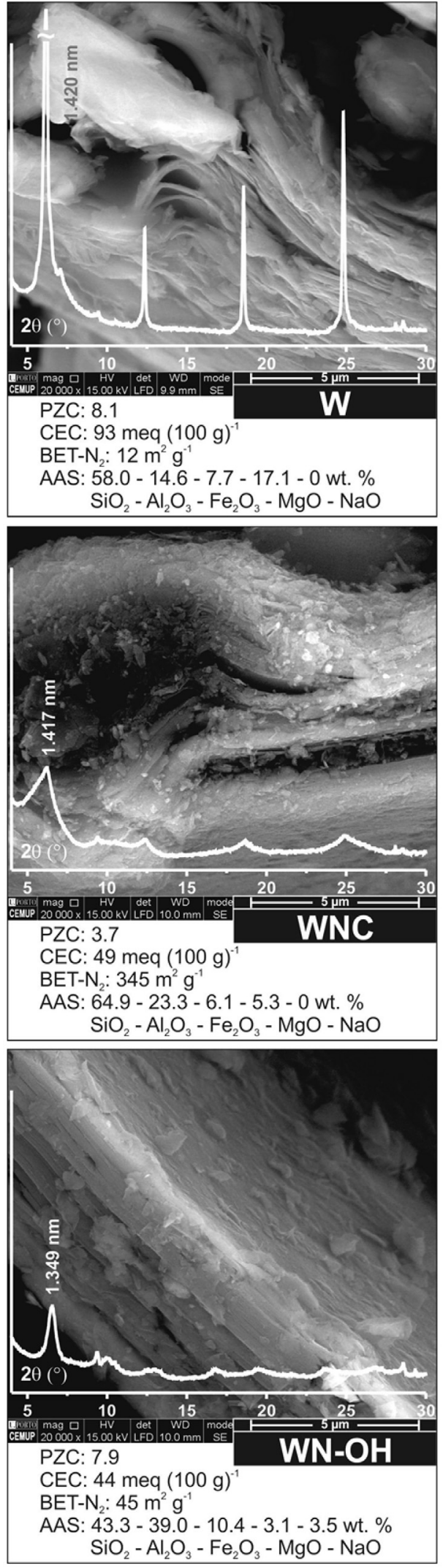

Fig. 1. Results of physicochemical characterization of acid-base treated vermiculite: particles morphology, XRD pattern, chemical composition, values of PZC, BET- $\mathrm{N}_{2}$ and CEC. 
Table 1

Parameters of kinetic and equilibrium equations obtained for adsorption of $\mathrm{MB}$ and $\mathrm{AR}$ on starting vermiculite (W), acid treated (WNC) and $\mathrm{NaOH}$ tre( $(\mathrm{Ak}$ eld-OH) vermiculite.

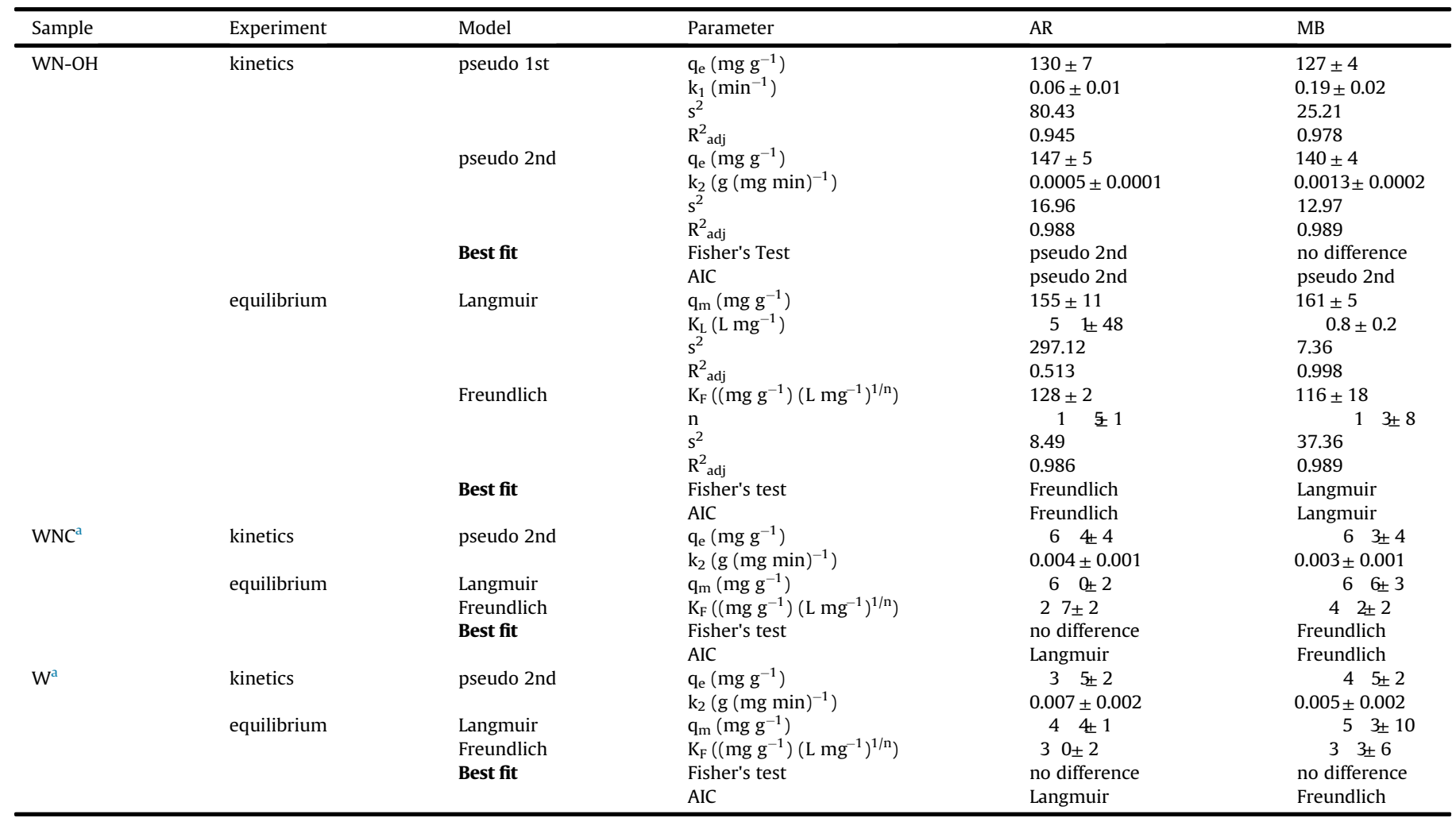

Bold indicates positions of results of model comparison according to Fisheifest and Akaikés Information Criterion.

a (Stawiński et al., 2016).

Ve $\mathrm{NaCl}$ ). Organic solvents Fig. 2) seem better for that purpose (Ve $\mathrm{EtOH}, \mathrm{Ve} \mathrm{MeOH}, \mathrm{Ve}$ Act), however, the best results were obtained when a solution containing both, organic and inorganic compounds, was used ( $\mathrm{Ve} \mathrm{EtOH}+\mathrm{NaCl}$, Ve $\mathrm{EtOH}+\mathrm{HNO} 3$ ). The results also showed that time plays an important role in regeneration process. Signficant increase in the regeneration effciency was observed after $24 \mathrm{~h}$ in comparison to $2 \mathrm{~h}$.

It was observed that methanol $(\mathrm{Ve} \mathrm{MeOH})$ desorbs better than ethanol (Ve EtOH) and the methanol-regenerated material showed adsorption capacity higher than the raw oneF(ig. 2). Mixture of

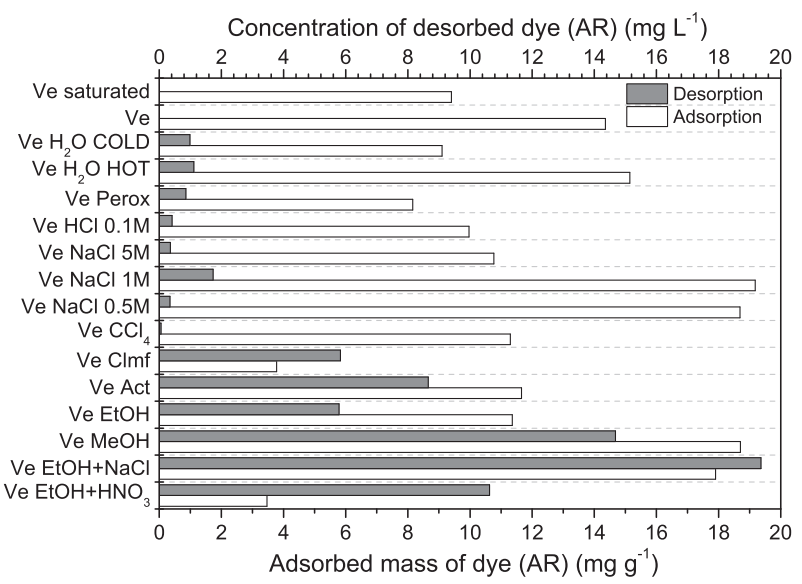

Fig. 2. Desorption efficiency after $2 \mathrm{~h}$ (bottom axis) from the expanded vermiculite (Ve) saturated with AR, and adsorption efficiency (top axis) on regenerated material (100 mL of $100 \mathrm{mg} \mathrm{L}^{-1} \mathrm{AR}$ solution, $2 \mathrm{~h}$ at $24^{\circ} \mathrm{C}$ ). ethanol and sodium chloride (WNC $\mathrm{EtOH}+\mathrm{NaCl}$ and $\mathrm{Ve}$ $\mathrm{EtOH}+\mathrm{NaCl}$ ) resulted in good desorption, also adsorption on the regenerated material is on the level of the starting oneF(g. 3). It should be noted that none of these solvents, ethanol or sodium chloride solution, is as effective as their combination.

\subsection{Column studies}

Results from column studies were adjusted to Yan's and YoonNelson's models (Tables A.1 and A.2 in the Supplementary Material). Experimental data withfitted Yan's model are shown in Fig. A.8 and Table A.1. The experiments colfirmed an increase in the

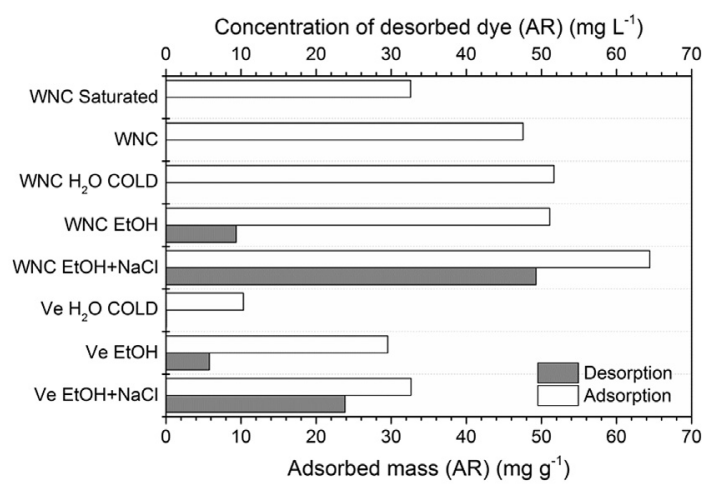

Fig. 3. Desorption efficiency after $24 \mathrm{~h}$ (bottom axis) from saturated materials (Ve and WNC) and adsorption efficiency (top axis) on regenerated material in selected conditions ( $100 \mathrm{~mL}$ of $100 \mathrm{mg} \mathrm{L}^{-1} \mathrm{AR}$ solution, $2 \mathrm{~h}$ at $24^{\circ} \mathrm{C}$ ). 
adsorption capacity of vermiculite on each step of the treatment. Higher adsorption capacities were obtained for MB on mofeed materials (WNC and $\mathrm{WN}-\mathrm{OH}$ ) with an exception for the starting vermiculite on which AR reached higher adsorption level compared to MB (Fig. 4A). After two cycles the breakthrough time stabilized at an average level of $144 \pm 15$ and $212 \pm 27$ min on the raw material, $114 \pm 25$ and $88 \pm 13 \mathrm{~min}$ on acid treated material, and 12325 and $99 \pm 8$ min on $\mathrm{NaOH}$ treated material, respectively for $\mathrm{MB}$ and $\mathrm{AR}$ (Fig. 4B).

Desorption studies showed that an average time of $100 \mathrm{~min}$ is enough to allow a satisfactory reuse of the column packing material (Fig. A.9 in the Supplementary Material). The experiments showed a general trend of changes in $\mathrm{pH}$ towards higher values in the case of AR and towards lower ones in the case of MBF(ig. A.10 and Fig. A.11 in the Supplementary Material). MB exhibited higher affinity to the material compared to AR which was being gradually desorbed from the column as adsorption of MB preceded (overshooting) when the column reached its maximum capacity. The values in that region were not considered during adjustments of the models. The materials showed higher adsorption capacity for MB compared to AR (Fig. 5). Table A.3 in the Supplementary Material contains full models' parameters.

\section{Discussion}

Vermiculite being a natural mineral, used without any additional purification, shows signficant variances in measured properties, thus two methods were used to determine the point of zero charge (PZC). Shift between the measured PZC values was observed in different electrolyte concentrations, with a tendency towards lower $\mathrm{pH}$ with an increase of the ionic strength. That indicates electrolyte adsorption causing a release of protons associated with cation exchange sites (Conklin, 2014). Particle charge was then neutralized not only by adsorption of $\mathrm{H}^{+}$and $\mathrm{OH}^{-}$but also electrolyte ions.

The $\mathrm{pH}$ measured when the following charges are neutralized: the charge depending on adsorbent structure (structural charge) and resulting from adsorption and immobilization of ions into surface complexes in adsorbent (net particle charge or net adsorbed surface charge), thus, a state when there is no more charge to be neutralized by ions in the diffuse layer, is simply called point of zero charge and corresponds to neutralization of net total particle charge (Sposito, 2008). PZC of raw vermiculite was found at about 8.1, which is in agreement with previous studies/(bollino et al., 2008; Fox and Malati, 1993. After treatment it shifted to 3.8, subsequent treatment with $\mathrm{NaOH}$ shifted the PZC back to

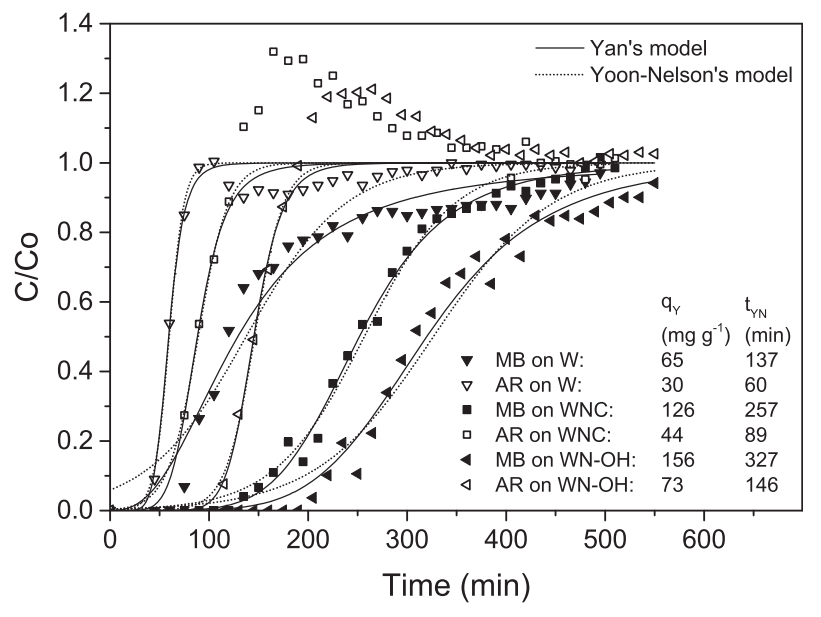

Fig. 5. Adsorption curves with models fitted to the experimental data of co-adsorption of $\mathrm{MB}$ and $\mathrm{AR}$ on starting $(\mathrm{W})$, acid treated $(\mathrm{WNC})$ and $\mathrm{NaOH}$ treated $(\mathrm{WN}-\mathrm{OH})$ material in column system; initial dyes concentrations: $50 \mathrm{mg} \mathrm{L}^{-1}$, flow rate: $2.0 \mathrm{~mL} \mathrm{~min}{ }^{-1}$, temperature $24{ }^{\circ} \mathrm{C}$.

approximately initial value of 7.9. Theinal product of acid treatment of clays is partly dissolved material of increased surface area, porosity and surface acidity, thefinal solid product also contains amorphous three-dimensional cross-linked silicaK(omadel and Madejova, 2006). Chemical decomposition of clays causes an evolution of the surface functional groups from the pre-eminence of the siloxane ditrigonal cavity to an increase in abundance of inorganic hydroxides, that are capable of being ionized in contact with water (Molina, 2013; Sposito, 1984. When the crystalline surface of phyllosilicates is distorted, unsaturatedbroken bonds' occur at the edge surface, these may be compensated by formation of reactive $\mathrm{OH}$ groups leading to Brønsted acid sites such as $\mathrm{SiOH}$ and coordinately unsaturated $\mathrm{Al}$ and $\mathrm{Mg}$ easily formed at the edges behave as Lewis acids (Komadel and Madejova, 200£. When OH group is coordinated to $\mathrm{Al}$ (III) they can form inner-sphere complexes with a proton or hydroxide anion depending on $\mathrm{pH}$ values, when coordinated to Si, they tend to complex only hydroxide anions. Such prepared clays are also riddled with defects (vacant Ion sites) that promote forming hollow spherule whose outer boundary contains many apertures through which small molecules or ions can enter (Sposito, 1984). Also the point of zero net charge (PZNC), thus PZC as well, for silica is relatively low (usually below 4)S(posito, 2008). Those factors caused the shift of PZC in the treated material. The treatment with citric acid causes dissolution of metal hydroxides by
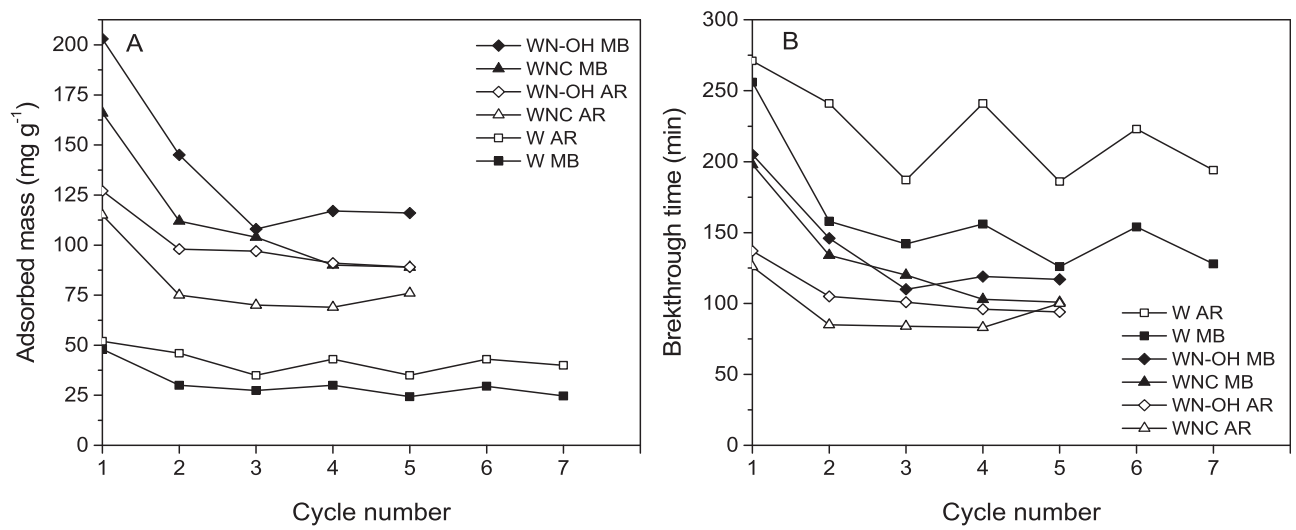

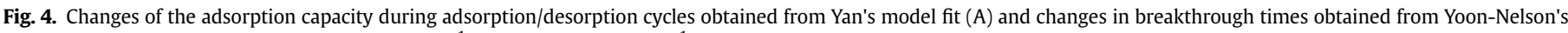

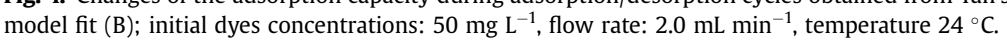


complexing the multivalent ions with citrate. Presence of such hydroxides prevents optimal dispersion of the clay causing coagulation and aggregation (Carrado et al., 2000). Citrate ions might also complex and remove the part of interlayer cations that had not been leached or exchanged during the mineral acid treatment and as well bulk metal oxides present on the layers surface. After the acid treatment deposits of amorphous silica, that act as a cementing agent impeding swelling and dispersion, are present in the material. During $\mathrm{NaOH}$ treatment that silica, as well as hydrous aluminoslicates (allophanes) formed during acid treatment, are dissolved (Carrado et al., 2006). This might clean the material and make the interlayer space more accessible for adsorption and removed degradation product responsible for lowering the PZC, as well as it was reported, the shift of PZC towards higher values is a normal phenomenon occurring in chemical weathering of clays provided that it involves removal of silica \$posito, 2008).

The specific surface areas of the materials obtained by $\mathrm{MB}$ method are signficantly higher than those from BET. This is due to the fact that specfic surface area is an operational concept and obtained values may differ depending on an experimental method used, thus it precludes any interpretation of its numerical values in absolute geometric sense. Hence there is no one spefic surface of a clay, but rather specfic surfaces (Sposito, 1984). N 2 adsorption method creates limitations in samples containing layer-silicates (Aringhieri et al., 1992) due to the relatively large Van der Waals radius of the $\mathrm{N}_{2}$ molecule that prevents it from interacting with surface functional group occluded in small void spaces and it is adsorbed only on the external surfaces of phyllosilicate quasicrystals (Sposito, 1984). The poor reactivity of non-polar molecule of $\mathrm{N}_{2}$ to exposed surfaces might also contribute to lowering the values of specific surface area (Aringhieri et al., 1992). Methylene blue molecule, on the other hand, can penetrate the structure of the material, enter interlayer regions and the siloxane ditrigonal cavities. Another factor affecting the obtained spefic surface area in $\mathrm{MB}$ experiment is the fact that the distribution of the dye cations on the surface of clays is iffluenced not only by electrostatic interactions, but also by dye-dye interactions (Lagaly et al., 2006). MB adsorption may follow the multilayer modelV(Veng and Pan, 2006) and on certain surfaces it can form dimmers or trimmers on the external surface of clay, which precedes the disaggregation and migration of the dyes in between the layers(yeumann et al., 2002). Decreasing particle size can increase the adsorption capacity since molecules don't penetrate the interlayer region but adsorb on the surface, smaller particles give larger surface areas. Also the inability to penetrate the micropores by large dyes molecules affects results obtained by dye adsorption!izge et al., 2008; Gupta et al., 2003). Although it seems there was a reduction of spefii surface area $\left(\mathrm{N}_{2}\right.$ adsorption method) after the base treatment, before that stage the total area available to adsorption was not accessible to the dyestuffs (inner surface of micropores). On the other hand, interlayers were not available to $\mathrm{N}_{2}$ molecules after outgassing (Fig. A.2), while they can be penetrated by adsorbate molecules in the solution. Diffusion into interlayer galleries is possible due to base treatment and removal of silica clusters binding adjacent layers.

The DRIFT analysis showed that the acid treatment resulted in an increase in intensity and width of the peaks in mentioned range due increase in heterogeneity of $\mathrm{OH}$ species in the material (Wegrzyn et al., 2013). NaOH treatment decreased sigificantly that intensity, due to washing off hydroxyl group bearing species. After the $\mathrm{NaOH}$ modfication hydrophilic cations of $\mathrm{Na}$ are present in the material strengthening the $\mathrm{H}$-bonding of the polarized water. When the H-bonding is stronger, lower energy is required for an occurrence of $\mathrm{OH}$-stretching vibration and thus the observed bands in $\mathrm{NaOH}$ treated vermiculite are shifter towards higher wavenumbers (Tomi ć et al., 2012). The bands in the spectrum of acid treated samples are broadened. This phenomenon may be due to decreasing crystallinity attributed to the weakening of H-bonds within the crystal and changes in $\mathrm{FeO}$ bonds associated with the tilting of octahedra rows within the structureP(arikh et al., 2014). Also it can be attributed to the partial transformation of the tetrahedral sublayers into a three dimensional framework of amorphous silica (Komadel et al., 1996; Madejová et al., 1998; Steudel et al., 2009). The shift of bands in the Si-O stretching region may correspond to progressive transformation of $\mathrm{SiO}-\mathrm{Mg}-\mathrm{O}-\mathrm{Si}$ bonds in the silicate to the more rigid $\mathrm{SiO}-\mathrm{Si}-\mathrm{O}-\mathrm{Si}$ bonds in amorphous silica when the octahedral cations were removed (Belver et al., 2002). Moreover, such shift in the band position of $\mathrm{Si}-\mathrm{O}$ stretching region was reported as a result of reduction of $\mathrm{Fe}^{3+}$ and increasing amount of structural $\mathrm{Fe}^{2+}$ (Stucki, 2006).

The XRD analysis showed that upon the acid treatment some amorphous species of silica appear in the materian(laqueda et al., 2007) however, the vermiculite structure is preserved although the crystallinity signficantly decreases. After the $\mathrm{NaOH}$ treatment the vermiculite structure changes, the material almost completely loses its crystallinity and some of the amorphous phase is leached from the material along with formation of another hydroxy phase.

Fisher's test showed no preference towards any model in the case of adsorption on the raw material and in the case of adsorption of AR on acid treated vermiculite. Adsorption of $\mathrm{MB}$ on acid treated material according to that testfits better to Freundlich's model, suggesting that it assumes multilayer adsorption on heterogeneous surface. AIC test however indicated Langmuir's model, which assumes monolayer adsorption on homogeneous surface, as a better fit in the case of adsorption of AR on the raw and acid treated material and Freundlich's in the case of adsorption of MB on those materials. The adsorption seems to change its mechanism after the material had been treated with $\mathrm{NaOH}$. The trend of adsorption of AR driven by Langmuir's model's assumptions changes to Freundlich's and the opposite happens in the case of MB, both tests indicated the same models as the bestfits in each case. Cation can be adsorbed on clays directly to the surface by forming an outer-sphere complexes as well as in a form of an outer-sphere complexes where water molecules are located between the cation and the clay surface (Sposito, 1984). Astrazon red is a bigger molecule so it should have lower ionic potential, which is a ratio of charge and molecule radius, compared to methylene blue, and that is why it has less affinity to the material. Additionally the interactions between the dyes and the clay are weakened due to decreasing of layer charge occurring during the dissolution of the vermiculite during the treatment. Such process also renders the layer charge distribution more heterogeneous (Pentr ák et al., 2012). Those facts may explain the change of adsorption mechanism of AR on $\mathrm{NaOH}$ treated material. Some of the molecules can migrate from the inner-sphere complexes and outer-sphere complexes forming multilayer, also AR is a moreflexible molecule and has more resonance structures than MB, which may allow different geometric coordination of the molecule on the surface making the layer more heterogeneous. The fact of MB tending to form multilayers might be explained by its ability to form dimmers and trimmers on external surfaces of adsorbents as afirst step followed by disaggregation and migration of dye molecules in between the layers (Neumann et al., 2002. Moreover after the acid treatment the sample contains amorphous material that may provide additional adsorption sites and as they occupy also micropores what impedes access to some internal structures rendering the surface more heterogeneousł(ajjaji and El Arfaoui, 2009). After the final step of treatment, during which the amorphous phase is leached, the material becomes more homogenous allowing MB to form more ordered layers on the surface and Langmuir's model becomes again the besfit. It has been 
reported (Pentr ák et al., 2012) that MB tends to form monolayer on clays with reduced layer charge due to their decomposition. Decreasing particle size can increase the adsorption capacity, since the dyestuff molecules don't penetrate the interlayer region but adsorb on the external surface which may be sigficantly higher for small particles. It has to be mentioned that no matter how good the fit of a model is, it does not mean that an actual phenomenon the model expresses takes place. Most of the time, adsorption is controlled by various factors. Thus the adsorption isotherms equation, as well as rate laws should be rather considered as curve fitting models without actual mechanistic sigfiicance as they do not always reflect the actual phenomena taking place. However they are useful means with predictive capability of the adsorption to design adsorption units flameed and El-Khaiary, 2008; Sposito, 2008).

Desorption studies showed promising results in terms of regeneration the material. It is shown that contact time plays an important role in this process. Better desorption results of methanol compared to ethanol might be attributed to the fact that methanol being a smaller and more polar molecule than ethanol has easier access the interlayer space it displaces the adsorbed dyes molecules and interlayer water more ffciently. However, methanol due to its toxicity was no longer considered in this research. Adsorption capacity of the material regenerated that way is higher than of the raw sample. This phenomenon can be attributed to so called propping-open procedure. Ethanol and methanol molecules, previously adsorbed onto the material, are exchanged and facilitate intercalation of bigger organic molecules, which are not intercalated directly but in a stepwise process I(agaly et al., 2006). Significant increase in the adsorption capacity of the material regenerated with a solution containing $\mathrm{NaOH}$ is due to changes in the structure of the material and its partial dissolution that causes significant loss of the sorbent mass. This is an undesired effect in this case of a material that is supposed to be used in continuous adsorption-desorption cycles. This process is discussed later in the article. Mixture of ethanol and sodium chloride and ethanol and sodium hydroxide give good desorption results, better than when the organic solvents are used isolated, due to enhanced adsorption of counter ions, in this case $\mathrm{Na}^{+}$, that occurs in the presence of organic solvents in the solution (agaly, 2006), thus removal of the adsorbed dyes is enhanced. This phenomenon can be explained by the fact that when ethanol is added to water it decreases the dielectric constant of the solution, thus the columbic attraction between exchangeable cations and negative silicate surface increases. The higher adsorption capacity of the regenerated material can be attributed to exchange of remaining interlayer divalent metal cations to sodium. This results in better delamination of the clay (Lagaly, 2006) and better accessibility of the surface to dyes. Also the saturated material still showed some adsorption abilities.

By means of the column experiments it was shown that the material can be re-used in several adsorption-regeneration cycles. The maximum adsorption capacity decreased during therst two cycles to maintain a stable level in the case of treated materials but reminded unchanged in the case of the raw vermiculite. This phenomenon can be explained in terms of the changes occurring during the acid/base treatment. The material becomes more porous and its specific surface increases. Some of the adsorption sites might not be available to the solvent to penetrate (micropores, interlayer spaces) thus not all of the dyes molecules are able to be displaced and desorbed. It was also noticed that the total capacity in the case of coadsorption was higher than in the case of systems with only one dye, it also proves that each dye might be adsorbed on different sites. Another factor contributing to lowering the capacity in adsorptionregeneration cycles is that the eluent reaches the mentioned structures and occupies them not allowing the dyes to adsorb there in a following cycle. Also some of the dye or eluent molecules might adsorb on the materials with creation of chemical bonds permanently being attached to the surface. After the two cycles equilibrium is reached and adsorption takes place in more available sites. In the case of the raw material, that has crystalline structure and is more ordered, the diffusion of the solvent is easier rendering the desorption more eficient. The affinity of a dye seems to be a determinant factor in the removal of adsorbed molecules/ions. The molecule with the lowest affinity will always break through the column first, followed by other components of the feed having higher affinity. Concentration overshooting of one of the component occurs at the column outlet when an ion or molecule being less strongly adsorbed is pushed further in the column by more slowly moving, more strongly adsorbed species. That results in an increase in the solution concentration at the outlet of the column that can be higher that the initial one. Another factor causing overshooting may be the interference of ions or molecules displaced by ion exchange from the adsorbent surface, by that which have higher ffitity to the adsorbent (Franca and Oliveira, 2010. The dye structure, molecular flexibility and differences in dimensions can iffuence the competition for the adsorption sites (uta and Visa, 2015). MB molecule is more rigid (heterocyclic aromatic rings), thus is has slower diffusion rendering the adsorption slower, but it is able to give use to a larger amount of adsorption sites (e.g., inside micropores). AR however, being moreflexible shows faster diffusion and adsorption process at the easily accessible sites.

\section{Conclusions}

Acid treatment of clays is a well-known procedure to increase their adsorption capacity. However, if such modication is followed by treatment with sodium hydroxide, which is reported in our work for the first time, it increases the adsorption properties even more. That treatment removes amorphous phase formed during the acid attack on the material, decreases its crystallinity and greatly increases its specfic surface area (MB method). Adsorbent prepared by consecutive acid and base mofication was successfully used in column recyclable system with a possibility of regeneration. The adsorption capacity of two cationic dyes in column studies, increased from $48 \pm 2$ to $203 \pm 4 \mathrm{mg} \mathrm{g}^{-1}$ for methylene blue on starting material and from $51+1$ to $127 \pm 2 \mathrm{mg} \mathrm{g}^{-1}$ for astrazon red on acid-base treated material. The loss of the adsorption capacity was observed only during thefirst two cycles, after that it maintained a stable level. Adsorption and regeneration was performed efficiently for 7 cycles. Acid-base treated vermiculite proved to be an economical, recyclable and high performance adsorbent.

\section{Acknowledgements}

This work is financed by Fundos FEDER from Programa Operacional Factores do Competitividade (COMPETE) and Fundos Nacionais from Fundação para a Ciência e a Tecnologia (FCT) within the scope of the project SFRH/BD/80537/2011 and by the European Union (FEDER funds through COMPETE) and National Funds (FCT), through project Pest-C/EQB/LA0006/2013. Part of the research was carried out with the equipment purchased thanks to thenancial support of the European Regional Development Fund in the framework of the Polish Innovation Economy Operational Program (contract no. POIG.02.01.00-12-023/08). To afinancing sources the authors are greatly indebted.

\section{Appendix A. Supplementary data}

Supplementary data related to this article can be found dtttp:// dx.doi.org/10.1016/j.chemosphere.2017.01.039 


\section{References}

Abollino, O., Giacomino, A., Malandrino, M., Mentasti, E., 2008. Interaction of meta ions with montmorillonite and vermiculite. Appl. Clay Sci. 38 (34), 227-236.

Ali, I., Asim, M., Khan, T.A., 2012. Low cost adsorbents for the removal of organic pollutants from wastewater. J. Environ. Manag. 113 (0), 17083.

Angin, D., Köse, T.E., Selengil, U., 2013. Production and characterization of activated carbon prepared from saflower seed cake biochar and its ability to absorb reactive dyestuff. Appl. Surf. Sci. 280 (0), 705710.

Aringhieri, R., Pardini, G., Gispert, M., Sole, A., 1992. Testing a simple methylene blue method for surface area estimation in soils. Agrochimica 36 (3), 22432

Ayranci, E., Duman, O., 2009. In-Situ UV-Visible spectroscopic study on the adsorption of some dyes onto activated carbon cloth. Sep. Sci. Technol. 44 (15), 3735-3752.

Bailey, S.W., Chairman, 1980. Summary of recommendations of AIPEA nomenclature committee on clay minerals. Am. Mineral. 65, 47.

Belver, C., Bañares Muñoz, M.A., Vicente, M.A., 2002. Chemical activation of a Kaolinite under acid and alkaline conditions. Chem. Mater. 14 (5), 2032043.

Bergaya, F., Lagaly, G., 2006. In: Bergaya, F., Theng, B.K.G., Lagaly, G. (Eds.), Handbook of Clay Science. Elsevier Ltd

Bhatnagar, A., Jain, A.K., 2005. A comparative adsorption study with different industrial wastes as adsorbents for the removal of cationic dyes from water. J. Colloid Interface Sci. 281 (1), 4955.

Carrado, K.A., Decarreau, A., Petit, S., Bergaya, F., Lagaly, G., 2006. In: Bergaya, F., Theng, B.K.G., Lagaly, G. (Eds.), Handbook of Clay Science. Elsevier Ltd

Chmielarz, L., Kuśtrowski, P., Zbroja, M., Rafalskałasocha, A., Dudek, B., Dziembaj, R., 2003. SCR of $\mathrm{NO}$ by $\mathrm{NH}_{3}$ on alumina or titania-pillared montmorillonite various modfied with $\mathrm{Cu}$ or $\mathrm{Co}$ : Part I. General characterization and catalysts screening. Appl. Catal. B Environ. 45 (2), 103116.

Conklin, A.R., 2014. Introduction to Soil Chemistry: Analysis and Instrumentation, second ed. John Wiley\& Sons, USA

Dizge, N., Aydiner, C., Demirbas, E., Kobya, M., Kara, S., 2008. Adsorption of reactive dyes from aqueous solutions byfly ash: kinetic and equilibrium studies. J. Hazard. Mater. 150 (3), 737746.

Duman, O., Ayranci, E., 2006. Adsorption characteristics of benzaldehyde, sulphanilic acid, and p-phenolsulfonate from water, acid, or base solutions onto activated carbon cloth. Sep. Sci. Technol. 41 (16), 36733692.

Duman, O., Ayranci, E., 2010. Adsorptive removal of cationic surfactants from aqueous solutions onto high-area activated carbon cloth monitored by in situ UV spectroscopy. J. Hazard. Mater. 174 (43), 359-367.

Duman, O., Tunç, S., 2008. Electrokinetic properties of vermiculite and expanded vermiculite: effects of $\mathrm{pH}$, clay concentration and mono- and multivalent electrolytes. Sep. Sci. Technol. 43 (14), 37553776.

Duman, O., Tunç, S., Gürkan Polat, T., 2015a. Adsorptive removal of triarylmethane dye (Basic Red 9) from aqueous solution by sepiolite as effective and low-cost adsorbent. Microporous Mesoporous Mater. 210, 176184

Duman, O., Tunç, S., Polat, T.G., 2015b. Determination of adsorptive properties of expanded vermiculite for the removal of C. I. Basic Red 9 from aqueous solution: kinetic, isotherm and thermodynamic studies. Appl. Clay Sci. 10910, 22-32.

Duta, A., Visa, M., 2015. Simultaneous removal of two industrial dyes by adsorption and photocatalysis on afly-ash-TiO2 composite. J. Photochem. Photobiol. A Chem. 306 (0), 21-30.

Forgacs, E., Cserháti, T., Oros, G., 2004. Removal of synthetic dyes from wastewaters: a review. Environ. Int. 30 (7), 953-971.

Fox, I., Malati, M.A., 1993. An investigation of phosphate adsorption by Clays and its relation to the problems of eutrophication of the river stour, Kent. J. Chem. Technol. Biotechnol. 57 (2), 97107.

Franca, A.S., Oliveira, L.S., 2010. In: Crini, G., Badot, P.M. (Eds.), Sorption Processes and Pollution : Conventional and Non-conventional Sorbents for Pollutant Removal from Wastewaters. Presses universitaires de Franche-Comte Besancon.

Freundlich, H.M.F., 1906. Über die adsorption in läsungen. Z. fur Phys. Chem. 57, $385-470$

Gupta, V.K., Ali, I., Suhas, Mohan, D., 2003. Equilibrium uptake and sorption dynamics for the removal of a basic dye (basic red) using low-cost adsorbents. J. Colloid Interface Sci. 265 (2), 257264.

Hajjaji, M., El Arfaoui, H., 2009. Adsorption of methylene blue and zinc ions on raw and acid-activated bentonite from Morocco. Appl. Clay Sci. 46 (4), 418421.

Hameed, B.H., El-Khaiary, M.I., 2008. Sorption kinetics and isotherm studies of a cationic dye using agricultural waste: broad bean peels. J. Hazard. Mater. 154 (1-3), 639-648.

Ho, Y.S., McKay, G., 1999. Pseudo-second order model for sorption processes. Process Biochem. 34 (5), 451-465.

Komadel, P., Madejova, J., 2006. In: Bergaya, F., Theng, B.K.G., Lagaly, G. (Eds.) Handbook of Clay Science. Elsevier Ltd

Komadel, P., Madejová, J., Janek, M., Gates, W.P., Kirkpatrick, R.J., Stucki, J.W., 1996 Dissolution of hectorite in inorganic acids. Clays Clay Miner. 44 (2), 22836.
Lagaly, G., 2006. In: Bergaya, F., Theng, B.K.G., Lagaly, G. (Eds.), Handbook of Clay Science. Elsevier Ltd

Lagaly, G., Ogava, M., Dekany, I., 2006. In: Bergaya, F., Theng, B.K.G., Lagaly, G. (Eds.), Handbook of Clay Science. Elsevier Ltd

Lagergren, S., 1898. About theory of so-called adsorption of soluble substances. Kongl. Vetenskaps Acad. Handl. 24, 439.

Langmuir, I., 1918. The adsorption of gases on plane surfaces of glass, mica and platinum. J. Am. Chem. Soc. 40 (9), 13611403.

Leitão, A., Serrão, R., 2005. Adsorption of phenolic compounds from water on activated carbon: prediction of multicomponent equilibrium isotherms using single-component data. Adsorption 11 (2), 167179.

Madejová, J., Bujdák, J., Janek, M., Komadel, P., 1998. Comparative FT-IR study of structural modfications during acid treatment of dioctahedral smectites and hectorite. Spectrochim. Acta Part A Mol. Biomol. Spectrosc. 54 (10), 1397406.

Mall, I.D., Srivastava, V.C., Agarwal, N.K., Mishra, I.M., 2005. Adsorptive removal of malachite green dye from aqueous solution by bagasslly ash and activated carbon-kinetic study and equilibrium isotherm analyses. Colloids Surfaces A Physicochem. Eng. Aspects 264 (13), 17-28.

Maqueda, C., Romero, A.S., Morillo, E., Pérez-Rodríguez, J.L., 2007. Effect of grinding on the preparation of porous materials by acid-leached vermiculite. J. Phys. Chem. Solids 68 (5-6), 1220-1224.

Molina, F.V., 2013. Soil Colloids: Properties and Ion Binding. CRC Press

Mular, A.L., Roberts, R.B., 1966. A simpfied method to determine isoelectric points of oxides. Trans. Can. Inst. Min. Metall. Petrol. 69, 438439.

Neumann, M.G., Gessner, F., Schmitt, C.C., Sartori, R., 2002. fluence of the layer charge and clay particle size on the interactions between the cationic dye methylene blue and clays in an aqueous suspension. J. Colloid Interface Sci. 255 (2), 254-259.

Pan, B., Pan, B., Zhang, W., Lv, L., Zhang, Q., Zheng, S., 2009. Development of polymeric and polymer-based hybrid adsorbents for pollutants removal from waters. Chem. Eng. J. 151 (1-3), 19-29.

Parikh, S.J., Goyne, K.W., Margenot, A.J., Mukome, F.N.D., Calderón, F.J., 2014. In: Donald, L.S. (Ed.), Advances in Agronomy. Academic Press,-1148.

Pentrák, M., Czímerová, A., Madejová, J., Komadel, P., 2012. Changes in layer charge of clay minerals upon acid treatment as obtained from their interactions with methylene blue. Appl. Clay Sci. 55 (0), 100107.

Reife, A., Freeman, H.S., 1996. Environmental Chemistry of Dyes and Pigments. John Wiley \& Sons, New York

Rieder, M., Cavazzini, G., Dyakonov, Y.S., Frank-Kamenetskii, V.A., Gottardi, G., Guggenheim, S., Koval, P.V., Müller, G., Neiva, A.M.R., Radoslovich, E.W., Robert, J.-L., Sassi, F.P., Takeda, H., Weiss, Z., Wones, D.R., 1998. Nomenclature of micas. Clays Clay Miner. 46 (5), 586595.

Rivera-Utrilla, J., Bautista-Toledo, I., Ferro-García, M.A., Moreno-Castilla, C., 2001. Activated carbon surface modications by adsorption of bacteria and their effect on aqueous lead adsorption. J. Chem. Technol. Biotechnol. 76 (12), 1209-1215.

Rozada, F., Calvo, L.F., Garēa, A.I., Martın-Villacorta, J., Otero, M., 2003. Dye adsorption by sewage sludge-based activated carbons in batch anfixed-bed systems. Bioresour. Technol. 87 (3), 224230.

Sposito, G., 2008. The Chemistry of Soils. Oxford University Press, New York

Sposito, G., 1984. The Surface Chemistry of Soils. Oxford University Press

Stawiński, W., Freitas, O., Chmielarz, L., Wgrzyn, A., Komedera, K., Btachowski, A., Figueiredo, S., 2016. The iffluence of acid treatments over vermiculite based material as adsorbent for cationic textile dyestuffs. Chemosphere 153, $11 \$ 29$.

Steudel, A., 2008. Selection Strategy and Moffication of Layer Silicates for Technical Applications. Univ.-Verlag Karlsruhe

Steudel, A., Batenburg, L.F., Fischer, H.R., Weidler, P.G., Emmerich, K., 2009. Alteration of swelling clay minerals by acid activation. Appl. Clay Sci. $44(-\mathcal{R})$, $105-115$.

Stucki, J.W., 2006. In: Bergaya, F., Theng, B.K.G., Lagaly, G. (Eds.), Handbook of Clay Minerals. Elsevier

Tomić, Z.P., Ašanin, D., Antić-Mladenović, S., Poharc-Logar, V., Makreski, P., 2012. NIR and MIR spectroscopic characteristics of hydrophilic and hydrophobic bentonite treated with sulphuric acid. Vib. Spectrosc. 58 (0), 95103.

Weng, C.-H., Pan, Y.-F., 2006. Adsorption characteristics of methylene blue from aqueous solution by sludge ash. Colloids Surfaces A Physicochem. Eng. Aspects 274 (1-3), 154-162.

Wegrzyn, A., Chmielarz, L., Zjeżdżałka, P., Jabło ńska, M., Kowalczyk, A., Żelazny, A., Vázquez Sulleiro, M., Michalik, M., 2013. Vermiculite-based catalysts for oxidation of organic pollutants in water and wastewater. Acta Geodyn. Geomater. 10 (3(171)), 341-352.

Yan, G., Viraraghavan, T., Chen, M., 2001. A new model for heavy metal removal in a biosorption column. Adsorpt. Sci. Technol. 19 (1), 2543.

Yoon, Y.H., Nelson, J.H., 1984. Application of gas adsorption kinetiesl. A theoretical model for respirator cartridge service life and its practical applications. Am. Ind. Hyg. Assoc. J. 45 (8), 517-524.5 